\title{
Systematic review of the effectiveness of carotid surgery and endovascular carotid stenting versus best medical treatment in managing symptomatic acute carotid artery dissection
}

\author{
Sherif Sultan ${ }^{1,2 \#} \wedge$, Niamh Hynes ${ }^{2 \#}$, Yogesh Acharya ${ }^{1,2} \wedge$, Edel Kavanagh ${ }^{2}$ Fionnuala Jordan $^{3}$ \\ ${ }^{1}$ Western Vascular Institute, Department of Vascular and Endovascular Surgery, University Hospital Galway, National University of Ireland Galway, \\ Galway, Ireland; ${ }^{2}$ Department of Vascular and Endovascular Surgery, Galway Clinic, Doughiska, Royal College of Surgeons in Ireland and National \\ University of Ireland, Galway affiliated Teaching Hospitals, Galway, Ireland; ${ }^{3}$ College of Nursing and Midwifery, National University of Ireland, \\ Galway, Ireland \\ Contributions: (I) Conception and design: S Sultan, N Hynes; (II) Administrative support: S Sultan, N Hynes, Y Acharya; (III) Provision of study \\ materials or patients: S Sultan, N Hynes, Y Acharya, E Kavanagh, F Jordan; (IV) Collection and assembly of data: S Sultan, N Hynes, Y Acharya, \\ E Kavanagh, F Jordan; (V) Data analysis and interpretation: S Sultan, N Hynes, Y Acharya, E Kavanagh, F Jordan; (VI) Manuscript writing: All \\ authors; (VII) Final approval of manuscript: All authors. \\ \#These authors contributed equally to this work as co-first authors. \\ Correspondence to: Prof. Sherif Sultan, MCh, MD, FRCS, FACS, PhD. Professor of Vascular Surgery, National University of Ireland, Galway, Ireland. \\ Email: sherif.sultan@hse.ie; sherif.sultan@nuigalway.ie.
}

\begin{abstract}
Cervical artery dissection (CeAD) with an intramural haematoma can lead to stroke risk, especially in young patients. We performed comprehensive searches of the Cochrane Stroke Group Trials Register, the CENTRAL, MEDLINE and EMBASE to review the effectiveness of surgical and endovascular interventions versus best medical treatment alone for symptomatic CeAD. Furthermore, we aim to elaborate on the phenotypic individual disease manifestations of spontaneous Cervical Artery Dissection (sCAD) and how they translate into stroke and risk of dissection recurrence. Primary outcomes were ipsilateral stroke and disability. Secondary outcomes were death, any stroke, or transient ischaemic attack, residual stenosis $>50 \%$, recurrence of CeAD, expanding pseudo-aneurysm or major bleeding. Our search yielded no randomised controlled trials and/or controlled clinical trials (CCTs) comparing either carotid surgery or endovascular therapy with optimal medical management; thus there was no evidence to support the use of any specific method for management of extracranial CeAD in patients who fail antithrombotic therapy. However, despite the absence of controlled studies to compare surgery or endovascular therapy in patients who fail antithrombotic therapy, carotid surgery in young patients can be justified as a personalized precision approach given the high morbidity and mortality in this age group.
\end{abstract}

Keywords: Cervical artery; dissection; management; systematic review

Submitted Nov 03, 2020. Accepted for publication Feb 04, 2021.

doi: 10.21037/atm-20-7279

View this article at: http://dx.doi.org/10.21037/atm-20-7279

\section{Introduction}

Cervical artery dissection (CeAD) with an intramural haematoma can lead to a stroke risk of $2-2.5 \%$ (1). CeAD accounts for $8 \%$ to $25 \%$ of stroke in patients under the age of 45 years $(2,3)$. Unfortunately, the incidence of stroke has increased by $43.8 \%$ in the last ten years, especially in those aged between 25 and 44 years, which could have profound socioeconomic consequences and long-term implications

^ ORCID: Sherif Sultan, 0000-0001-8767-4929; Niamh Hynes, 0000-0002-6133-3322; Yogesh Acharya, 0000-0003-1829-5911. 
for quality of life $(4,5)$. Furthermore, the actual incidence of symptomatic spontaneous CeAD is usually under reported, as many cases are undiagnosed because they are asymptomatic or associated with mild transient neurological symptoms, such as temporary slurring of speech, numbness or pins and needles in the face or limbs. In young and middle-aged patients, CeAD is particularly belligerent (1). The underlying pathogenesis is still not clearly defined, therefore, efforts to reduce incidence, recurrence, and severity are difficult to implement (6).

CeAD could result in intramural haematoma resulting in stenosis or occlusion and cerebral ischemic events. These ischemic events are more often embolic rather than hemodynamic compromise. Emboli arising from the thrombus on the injured intima are managed by medical, surgical or endovascular intervention, especially for fear of further trashing of the brain (7). Considering that most patients present with ischaemic events and the pathological process relates to clot formation and embolization, antithrombotic and antiplatelet medications have been shown to be safe and equivalent (8). As such, many physicians opt to treat patients with CeAD by using medical therapy alone and reserve surgical or endovascular intervention for those in whom neurological symptoms do to not resolve, or reoccur $(9,10)$.

Some authors have demonstrated favourable longterm outcomes from carotid surgical intervention for symptomatic CeAD $(11,12)$. However, others have shown poor outcomes (13) and most of them blame these unfavourable outcomes on difficulties in the preparation of the dissected carotid artery and associated cranial nerve injury. Poor surgical outcomes have inspired the application of endovascular interventions, despite no clear supportive evidence (14-17). Surgical intervention is limited to patients who develop neurological symptoms or have a progressive clinical course despite medical therapy, as long as they have anatomically accessible lesions and endovascular therapy is deemed high risk in young patients or is contraindicated (7). These clinical management algorithms; however, are not based on level one evidence and are influenced by anecdotal experience or local expertise.

A previous Cochrane review showed that anticoagulants were associated with reduced risk of death and disability compared to anti-platelet therapy; however, these apparent benefits were offset by a nonsignificant risk of major intracerebral and extracerebral bleeding (18). Due to a lack of robust evidence, treatment algorithms describing when and how to intervene have not been adequately developed for patients who remain symptomatic, with evolving neurological defects, despite medical management. Factors, which confound therapeutic decisions and are particularly pertinent in the setting of CeAD include, the patients' young age, the possibility of an underlying connective tissue disorder and the increased risk of stroke when surgical or radiological intervention is undertaken during the acute phase. As there is no consensus on how best to manage patients with symptomatic $\mathrm{CeAD}$, we aim to perform a systematic review to assess the effectiveness of surgical and endovascular interventions versus best medical treatment alone for symptomatic CeAD. Furthermore, we would like to elaborate on the phenotype of the individual disease manifestations concerning spontaneous $\mathrm{sCAD}$ and how they translate into stroke and risk of dissection recurrence, and set up an algorithm for symptomatic CeAD management. We present the following article in accordance with the PRISMA checklist (available at http://dx.doi.org/10.21037/atm20-7279).

\section{Methods}

This systematic review was undertaken in accordance with the recommendations described in the Cochrane Handbook for Systematic Reviews of Interventions (19-21).

Careful consideration was given to the participants, interventions, comparators and interventions (PICO). PICO was then used to formulate the review question, title, objective and search strategy, and provide a rationale for the objective of the review (22) (Appendix 1).

\section{Search methods for identification of studies}

We employed the search in the Cochrane Central Register of Controlled Trials (CENTRAL) (Cochrane Library; latest issue) in the Cochrane Library, MEDLINE Ovid (from 1946), and Embase Ovid (from 1974). The subject strategies for databases were modelled on the search strategy designed for MEDLINE Ovid. Subsequently, we also searched the ongoing trials registers: US National Institutes of Health Ongoing Trials Register ClinicalTrials.gov; World Health Organization International Clinical Trials Registry Platform; and Stroke Trials Registry.

In an effort to identify further published, unpublished, and ongoing trials, we conducted the secondary searches: bibliographies of included studies and any relevant systematic reviews identified for further references to relevant trials and used the Web of Science cited reference search to forward track relevant references; contacted original authors 
for clarification and further data on trial reports that were unclear; and contacted experts, trialists, or organisations in the field to obtain additional information of any unpublished or ongoing clinical trials data and/or information.

\section{Criteria for considering studies for this review}

\section{Types of studies}

The methodological approaches undertaken in this review were agreed on a priori. Only the RCTs and controlled clinical trials (CCTs) were employed to determine the effectiveness of an intervention. Well-designed RCTs seek to overcome selection bias for participants by using strict inclusion criteria and random sequence generation and allocation concealment. CCTs work on the same principles as RCTs, and although they do not include random sequence generation and thus may be open to bias, the prospective methodology reduces the likelihood of recall bias. The inclusion of CCTs was seen to be worthwhile to expand the number of possible studies without compromising objectivity, once they were subject to rigorous assessment of bias testing.

\section{Types of participants}

Participants' were chosen to maintain a sufficient clinical equipoise on optimal clinical management. Patients presenting with $\mathrm{CeAD}$ are treated by clinical consensus with antithrombotic medication. However, if this medication fails the choice on the mode of intervention that best serves is not yet evidence-based.

\section{Types of interventions}

The interventions of interest were endovascular intervention (angioplasty and/or stenting) and open carotid surgical repair. These interventions are reflective of contemporary clinical practice, and treatment options available.

\section{Comparator intervention}

The comparator was antithrombotic therapy and included anticoagulant, antiplatelet and thrombolytic therapies, none of which required invasive intervention.

\section{Outcomes}

The clinically relevant outcomes were based on clinical experience and international guidelines and outcomes, which were deemed most reflective of the impact on individual patients and healthcare resources (22-25).

\section{Primary outcomes}

(I) Ipsilateral stroke (26).

(II) Disability defined according to the modified Rankin Scale (27).

Endpoints were assessed at early (0-1 month), midterm (1-3 months), late (3 months -1 year), and extended ( $>1$ year) time points, as applicable.

\section{Secondary outcomes}

(I) Death;

(II) Any stroke, or TIA, residual stenosis (>50\%);

(III) Recurrence of cervical dissection, in either the same artery, or any of the other three extracranial cervical arteries;

(IV) Expanding pseudoaneurysm;

(V) Major bleeding.

\section{Study eligibility criteria}

\section{Inclusion criteria}

All RCTs and CCTs assessing the effects of open surgical repair and/or endovascular repair of symptomatic extracranial cervical dissection compared to medical therapy alone were eligible for inclusion. Participants with a clinical diagnosis of symptomatic extracranial carotid artery and/ or vertebral artery dissections were eligible for inclusion if associated with active neurological symptoms. Neurological symptoms included stroke, TIA or local neurological deficit, haemodynamic brain ischaemia, and/or expansion of concomitant pseudoaneurysm with neurological symptoms.

We included trials comparing surgical and radiological interventions with best medical therapy and considered the following comparisons: radiological intervention plus medical therapy versus medical therapy alone; and surgical interventional plus medical therapy versus medical therapy alone. Thrombolysis was not examined specifically, but patients who have had a trial of thrombolysis prior to surgical or radiological intervention were not excluded.

\section{Exclusion criteria}

We excluded studies that failed to include at least one primary outcome, reported on a single treatment modality, had three or fewer cases, consisted of reviews summarising case series, series with data already reported in previous citation, and studies in which discrimination 
could not be made between common carotid artery, internal carotid artery, vertebral artery or intracerebral artery dissection. We did not exclude studies based on age, gender, stage or severity of the condition, aetiology or comorbidities.

\section{Data extraction and management}

It was planned for data to be extracted independently from the included studies, using an adapted data extraction form. The authors independently screened titles and abstracts of the references obtained as a result of our searching activities. We obtained the full-text articles for the remaining references retrieved, and review authors (SS, NH) independently screened the full-text articles and identified whether studies were eligible for inclusion, and identified and recorded reasons for exclusion of the ineligible studies. Any disagreements were resolved through discussion and when required, a third author (FJ) was consulted. Multiple reports of the same study were collated so that each study, not each reference, is the unit of interest in the review. Subsequently, selection process was recorded to complete a PRISMA flow diagram.

\section{Assessment of risk of bias in included studies}

Two review authors (NH, and SS) planned to independently assess risk of bias for each study using the criteria outlined in the Cocbrane Handbook for Systematic Reviews of Interventions (19). Any disagreements were due to be resolved by discussion and by involving another author (FJ). The risk of bias were due to be assessed according to the following domains: random sequence generation, allocation concealment, blinding of participants and personnel, blinding of outcome assessment, incomplete outcome data, selective outcome reporting, and other bias. The risks of bias for each domain were due to be graded as high, low or unclear, and information from the study report was expected to be provided with a justification for our judgment in a 'Risk of bias' table.

\section{Measures of treatment effect}

Results of the dichotomous outcome measures were due to be expressed using risk ratio (RR) and associated $95 \%$ confidence intervals (CI) to reflect uncertainty of the point estimate of effects. For continuous outcome measures, we planned to calculate mean and standard deviation with the corresponding 95\% CI. Standardised mean difference (SMD) with $95 \%$ CI was due to be employed to combine outcomes from trials that measure outcomes using different scales (19). Similarly, survival analysis was planned to be used to report time-to-event data and the intervention effect expressed as a hazard ratio (HR) and associated $95 \%$ CIs. Methods planned to be used to analyse time-to-event data were to be guided by those described by Parmar et al. (28) and Tierney et al. (29).

\section{Dealing with missing data}

Missing and unclear data were due to be recorded for each included study. Where possible, all analyses was due to be performed using an intention-to-treat approach, i.e., anticipated analysis of all participants and their outcomes within the groups to which they were allocated, regardless of whether they received the intervention. When necessary, study authors were contacted to request missing data.

\section{Assessment of beterogeneity}

Assessments of clinical heterogeneity would have been determined by participant data, the intervention and outcomes of individual studies. Visual inspection of forest plots and examination of the $\mathrm{Chi}^{2}$ test, $\mathrm{I}^{2}$ and $\mathrm{Tau}^{2}$ statistic was planned to be used for determining heterogeneity of the outcomes (19). Statistical heterogeneity was considered as substantial if an $\mathrm{I}^{2}$ is greater than $50 \%$ and either the $\mathrm{T}^{2}$ is greater than zero, or there is a low $\mathrm{P}$ value (less than 0.10 ) in the $\mathrm{Chi}^{2}$ test for heterogeneity.

\section{Assessment of reporting biases}

Funnel plots were due to be employed as recommended by the Cochrane Handbook for Systematic Reviews of Interventions (19) for publication bias.

\section{Data synthesis}

$\operatorname{RevMan}^{\circledR} 5.4$ was planned to be used for pooled analysis using a fixed-effect analysis for synthesizing data where it is reasonable to assume that trials are estimating the same underlying treatment effect (30). If there were clinical heterogeneity sufficient to expect that the underlying treatment effects differ between trials, or where substantial statistical heterogeneity was detected, random-effects analysis would have been employed 
to produce an overall summary where the average treatment effect is clinically meaningful. If there was identified substantial clinical, methodological or statistical heterogeneity across included trials, a narrative approach to data synthesis would have been used instead of the pooled outcomes (19).

\section{GRADE}

Five GRADE considerations (study limitations, consistency of effect, imprecision, indirectness and publication bias) were planned to be used to assess the quality of a body of evidence as it relates to the studies that could have contributed data to the meta-analyses for the pre-specified outcomes (31). Justification would have been made on all decisions to down- or up-grade the quality of studies using footnotes, with comments to aid the reader's understanding of the review, where necessary.

\section{Subgroup analysis and investigation of beterogeneity}

Subgroup analyses were anticipated to be limited to primary outcomes. Planned subgroup analyses included, (I) vertebral artery dissection versus carotid artery dissection, (II) single versus multiple concomitant cervical arterial dissection, (III) presence versus absence of connective tissue disorder, (IV) traumatic (including iatrogenic), i.e., as a result of injury versus spontaneous, i.e., without a precipitating cause, and (V) surgical intervention with optimal medical management versus radiological intervention with optimal medical management.

\section{Sensitivity analysis}

We planned to repeat the analyses including high quality trials only. For the purpose of this review, trials judged 'low risk of bias' for sequence generation and allocation concealment would have been classified as high quality trials.

\section{Results}

The search generated 8,082 references. A total of 463 duplicates were identified and removed. The titles and abstracts of the remaining 7,619 studies were then reviewed. Of the 7,619 studies reviewed, we only carried forward 42 studies to full text review, and included or excluded studies based on study type and PICO, as outlined in the PRISMA flow diagram (Figure 1).

\section{Included studies}

None of the studies met the inclusion criteria.

Following full text review, we excluded all the final 42 studies from further analysis. Twenty studies were excluded based on wrong study design [Arauz, 2006 (32); Biller 1986 (33); Biousse 1994 (34); Biousse 1988 (35); Bogousslavsky 1987 (36); Campos 2004 (37); Caplan 2008 (10); Ehrenfeld 1976 (38); Guillon 1999 (39); Jensen 2017 (40); Lee 2006 (41); Lichy 2015 (23); Mokri 1990 (42); Mokri 1986 (43); Molina 2000 (44); Schievink 1994 (45); Sturzenegger 1995 (46); Vanneste 1984 (47); Watridge 1989 (48); Zelenock 1982) (49)]; 16 studies based on wrong intervention [Bakke 1996 (50); Bassetti 1996 (51); Beletsky 2003 (52); Campos 2007 (53); Caso 2004 (54); Cervical Artery Dissection in Stroke Study Trial Investigators 2007 (35); Cimini 2004 (55), Engelter 2012 (56); Engelter 2000 (57); Engelter 2009 (58); CADISS Investigators 2015 (8); Kennedy 2012 (59); Machet 2013 (60); TREATCAD 2014 (61); Touze 2001 (62); Weimar 2010 (63)]; 4 studies had the wrong outcomes [Bassi 2003 (64); Biousse 1995 (65); Larsson 2017 (66); Pieri 2007 (67)]; one study was based on wrong indication [Arnold 2009 (68)] and one study was based on wrong patient population [Marnat 2016 (69)] (Table 1).

\section{Characteristics of the excluded studies}

\section{Studies awaiting classification}

No studies are awaiting classification.

\section{Ongoing studies}

There are no on-going studies that specifically investigate surgical or endovascular intervention for patients who have failed medically therapy.

\section{Discussion}

There is a lack of evidence in the management of CeAD once medical treatment has failed. The only randomised controlled trials that were found in this systematic review were those, which enrolled patients with CeAD and randomised them to either anti-platelet medication or anticoagulation. Since the patient population for these trials was those presenting with their first CeAD, i.e., they had not yet had the opportunity to fail medical therapy, therefore, they did not match the PICO for this review and 


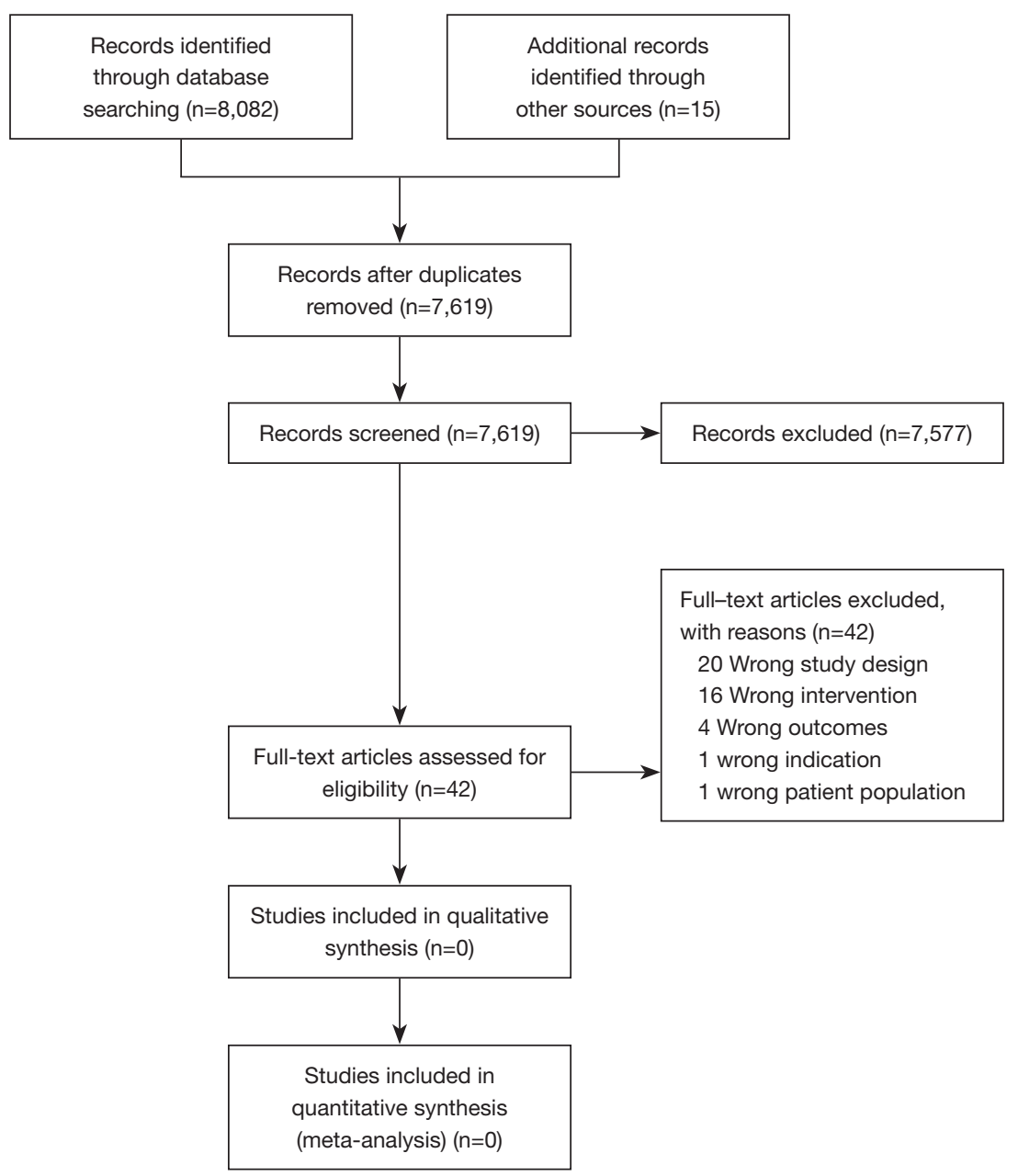

Figure 1 PRISMA flow diagram.

were not analysed.

The CADISS study was the only noteworthy RCT in this field (8). This trial compared anti-platelets to anticoagulants in patients with CeAD, which became clinically apparent within 7 days prior to randomization. The primary outcome in this trial was ipsilateral stroke or death of all causes within 3 months. The trialists found no difference in efficacy of antiplatelet and anticoagulant drugs at preventing the primary endpoint of stroke. They conclude that stroke in both groups is $2 \%$, and that this rate was lower than seen in observational trials. At first glance, one could argue that this undermines the need for the systematic review, as there is seldom a need for either endovascular or surgery. However, on closer inspection, it was noted that 52 patients, consisting more than $20 \%$ of the study population, were incorrectly diagnosed. On central review of the imaging, these 52 patients did not have radiographic evidence of CeAD and should therefore not have been enrolled in the study. Not only does this weaken the power of the study conclusions, it potentially underestimates the requirement for secondary intervention, because once these patients were excluded the stroke rate rose by $50 \%$.

One of the issues with an RCT in CeAD is that in order to sufficiently power a study, large numbers of patients are required for the clinical endpoint of stroke or neurological symptoms. This is all the more pertinent when attempting to enroll patients in whom medical therapy has failed because the population at risk is even smaller. Estimates based on the meta-analyses, in particular, four meta-analyses, which are based on observational studies comparing antiplatelet to antithrombotic medication, suggest that an RCT based on pure clinical 
Table 1 Characteristics of all the excluded studies with reason for exclusion

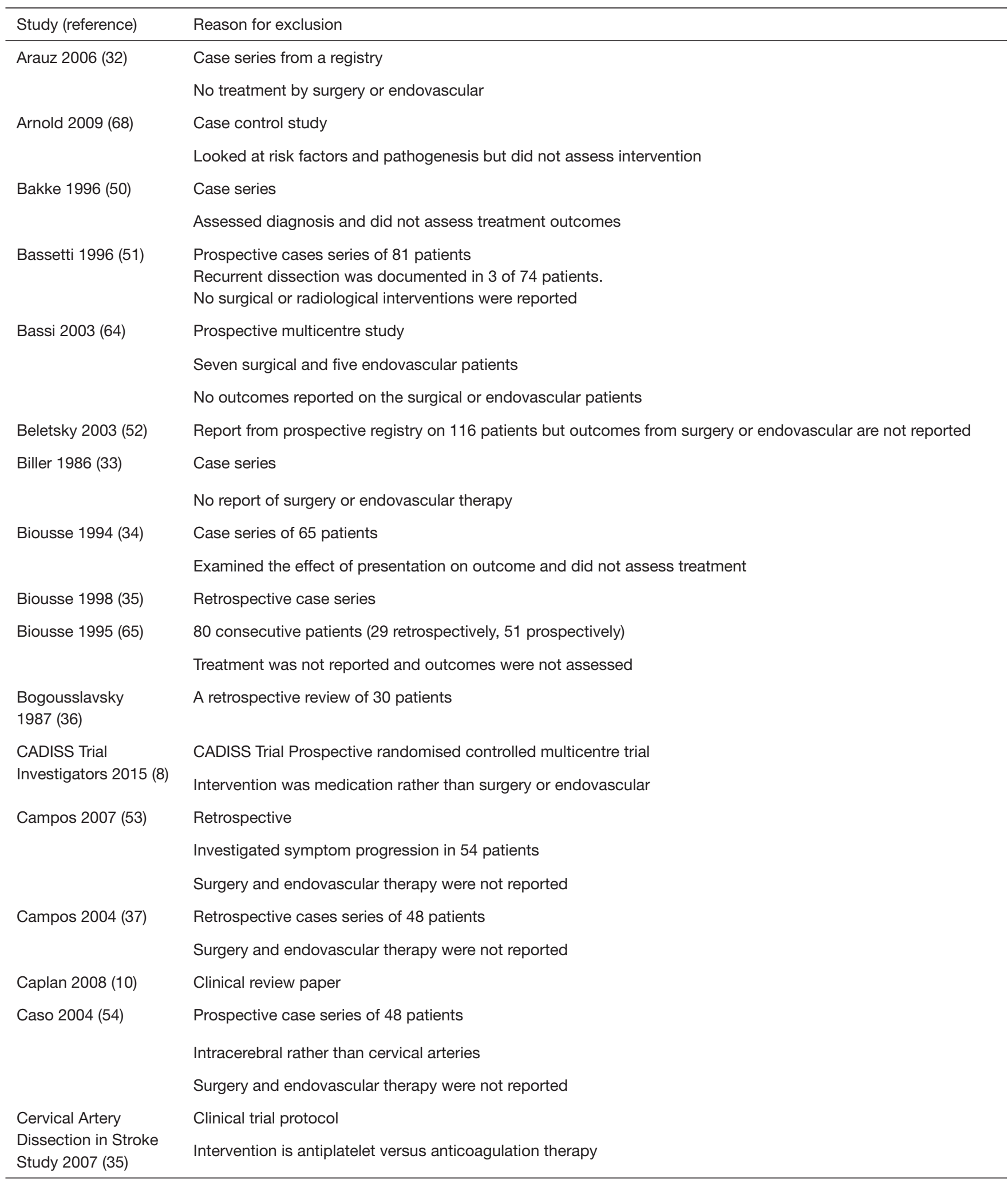

Table 1 (continued) 
Table 1 (continued)

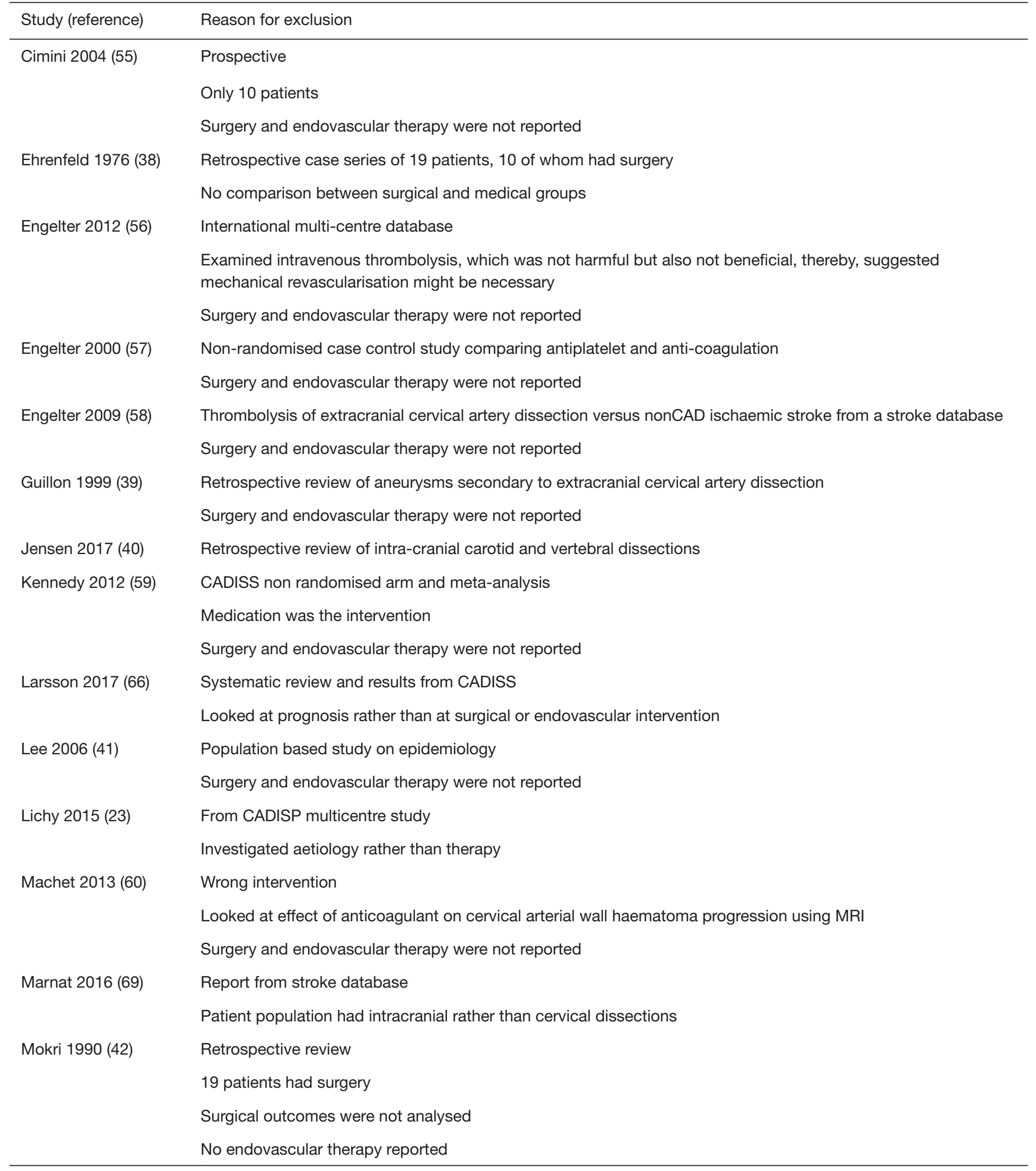

Table 1 (continued) 
Table 1 (continued)

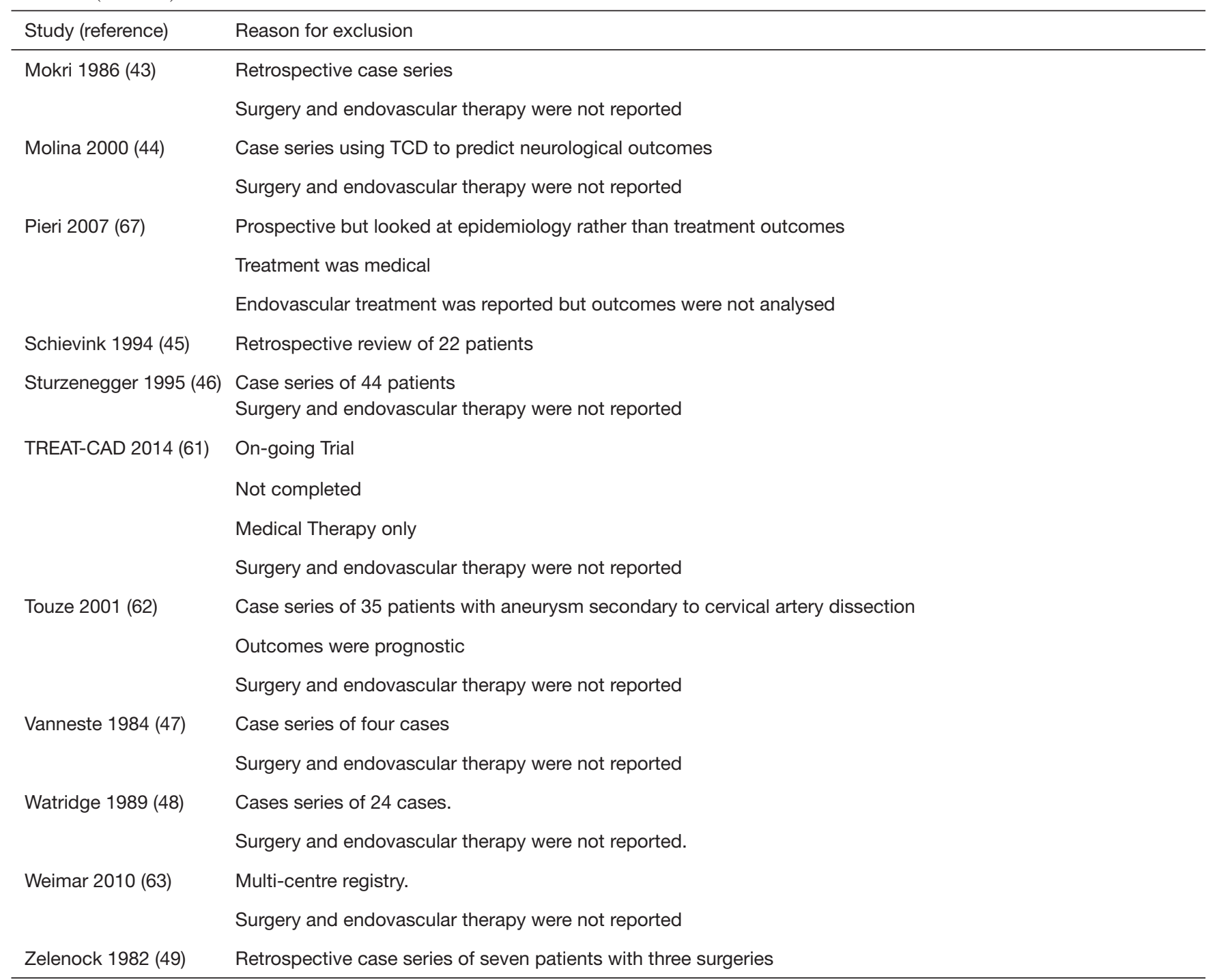

outcomes may require a sample size as large as 2,000 participants $(18,59,70,71)$.

Therefore, alternative surrogate outcome markers may be needed to compare treatments in this patient population. An example of a proxy marker for ischaemic events secondary to CeAD is diffusion-weighted MRI (DWI). An RCT comparing surgery to endovascular stenting in carotid stenosis demonstrated that usage of DWI as an alternative outcome marker revealed equivalent results as the clinical study (72). Similarly, when investigating carotid revascularisation, adding new silent microbleeds in MRI has been shown to be useful as a proxy for intracranial haemorrhage (73). The use of imaging endpoints has been tested in CeAD, whereby magnetic resonance surrogates are being used to compare aspirin to anticoagulant treatment, in an open-labelled, multicentre, noninferiority RCT (74).

Imaging endpoints are not the only ones, which have been used to supplement clinical or neurological endpoints. The Biomarkers and Antithrombotic Treatment in Cervical Artery Dissection (TREAT-CAD) study, which has been recruiting patients since September 2013, aims at demonstrating non-inferiority of aspirin compared with vitamin $\mathrm{K}$ antagonists in CeAD patients. The endpoints in this study include biomarkers, MMP9 and TIMP2, in addition to a composite outcome of clinical or imaging endpoints of brain ischemia, bleeds, or death (61). The 
expansion of endpoints and the prospect for reducing the scale of the numbers needed to recruit may make it more feasible to run RCTs and CCTs, especially in when evaluating invasive therapies.

Endovascular intervention is usually reserved for CeAD patients with recurrent ischaemic events despite antithrombotic therapy, when ruptured infarction is impending, in ruptured dissecting CeAD patients or in iatrogenic CeAD (7). Although we did not identify any RCTs or CCTs comparing endovascular therapy and antithrombotic treatment to antithrombotic therapy alone, we did find reports on endovascular treatment using angioplasty and stenting in CeAD patients, which did not meet the inclusion criteria $(15,75-78)$. The evidence pertaining to endovascular intervention arises from case reports and case series, which are highly selective and publish only successful interventions. Although collation of this data demonstrates good technical success, the majority of reported cases are on traumatic dissection, which represents a different disease aetiology and patient population than those with spontaneous dissection (79).

One systematic review of endovascular stenting in extracranial CeAD identified 140 patients (153 arteries) with extracranial internal carotid dissection (ICAD) and ten patients (12 arteries) with extracranial vertebral artery dissection (VAD) (79). The aetiology was mixed with $48 \%$ $(\mathrm{n}=64)$ traumatic, $37 \%(\mathrm{n}=49)$ spontaneous and $16 \%(\mathrm{n}=21)$ iatrogenic. The combined technical success rate was high at $99 \%$ for ICAD and $100 \%$ for VAD with low peri-procedural complications (1.3\% for ICAD and $0 \%$ for VAD). However, thrombosis of the stents occurred in 3 ICAD cases $(3 / 150$, $2 \%)$ and $1 \mathrm{VAD}$ case $(1 / 7,14 \%)$. Within a mean follow-up period of 17.7 months (range, 1-72 months), there were no deaths, and neurological complications occurred in $1.4 \%$ ICAD and 0 cases of VAD. The patient population included in these cases was not the same as that chosen in our review, i.e., active neurological symptoms despite antithrombotic therapy.

In $70 \%$ of all the reported cases, endovascular treatment was chosen because of contraindications for the use of anticoagulants or because of the severity of the hemodynamic compromise with or without failure of the antithrombotic treatment. An additional rare indication for endovascular stenting was rupture of an extracranial dissecting aneurysm (80). From this collated data it would appear that endovascular treatment seems relatively safe, however, an RCT would be needed to identify superiority over antithrombotic treatment alone. In the absence of level one evidence, carotid surgery and endovascular intervention are reserved for CeAD patients in whom antithrombotic therapy has failed, especially those patients who demonstrate rapid deterioration with impending hemodynamic infarction, and those with ruptured dissecting iatrogenic CeAD. However, one must bear in mind that these choices are not evidenced based and are subject to selective reporting bias and confounded by the experience of the operator, their training and individual preferences and skills.

Three studies, which were brought to full paper review, but were ultimately excluded, reported on surgical intervention $(38,42,49)$. The numbers are small $(42,49)$. A Cochrane systematic review reported collated data across cases series and found $135 \mathrm{CeAD}$ patients who had arterial surgery for ICAD (18). Ten (7.4\%) patients died and 7 (5.2\%) had a residual neurological deficit, which rendered them disabled. In particular, 7 (5.2\%) patients suffered from a stroke and $2(1.5 \%)$ experienced an intracranial haemorrhage. These morbidity and mortality rates exceed those reported from antithrombotic agents. The adverse outcomes from surgery more likely represent selection bias, because patients who had surgery were likely to be more severely affected at presentation, have had more extensive disease and demonstrated disease progression despite medical therapy, due to severe, recurrently symptomatic stenosis or persistent emboli (81). Surgical treatment when undertaken reportedly carries risks of early occlusion, stroke, and cranial nerve injuries (13). Therefore with the observational data that it is available, it seems surgery is directed to those cases of progression of symptoms where the lesions are anatomically challenging and complex and / or endovascular therapy is contraindicated (81).

\section{Authors algorithm in management of symptomatic patients with acute carotid artery dissection}

Over two decades, we have had more than 19,000 carotid artery referrals to our vascular laboratory; and we operated on approximately 1,100 patients $(5.7 \%)$. We identified 73 symptomatic patients $(6.3 \%)$ with acute carotid dissection, all below 55 years of age and $90 \%$ are female. The majority related their symptoms to trauma, such as chiropractor manipulation, stretching on a reformer during a pilate session, dental, and hairdresser manipulations. One third of the patients had a diagnosis of a connective tissue disorder. We operated on 11-post failure of optimal medical therapy (15\%); two of which, had a genetic disorder. 


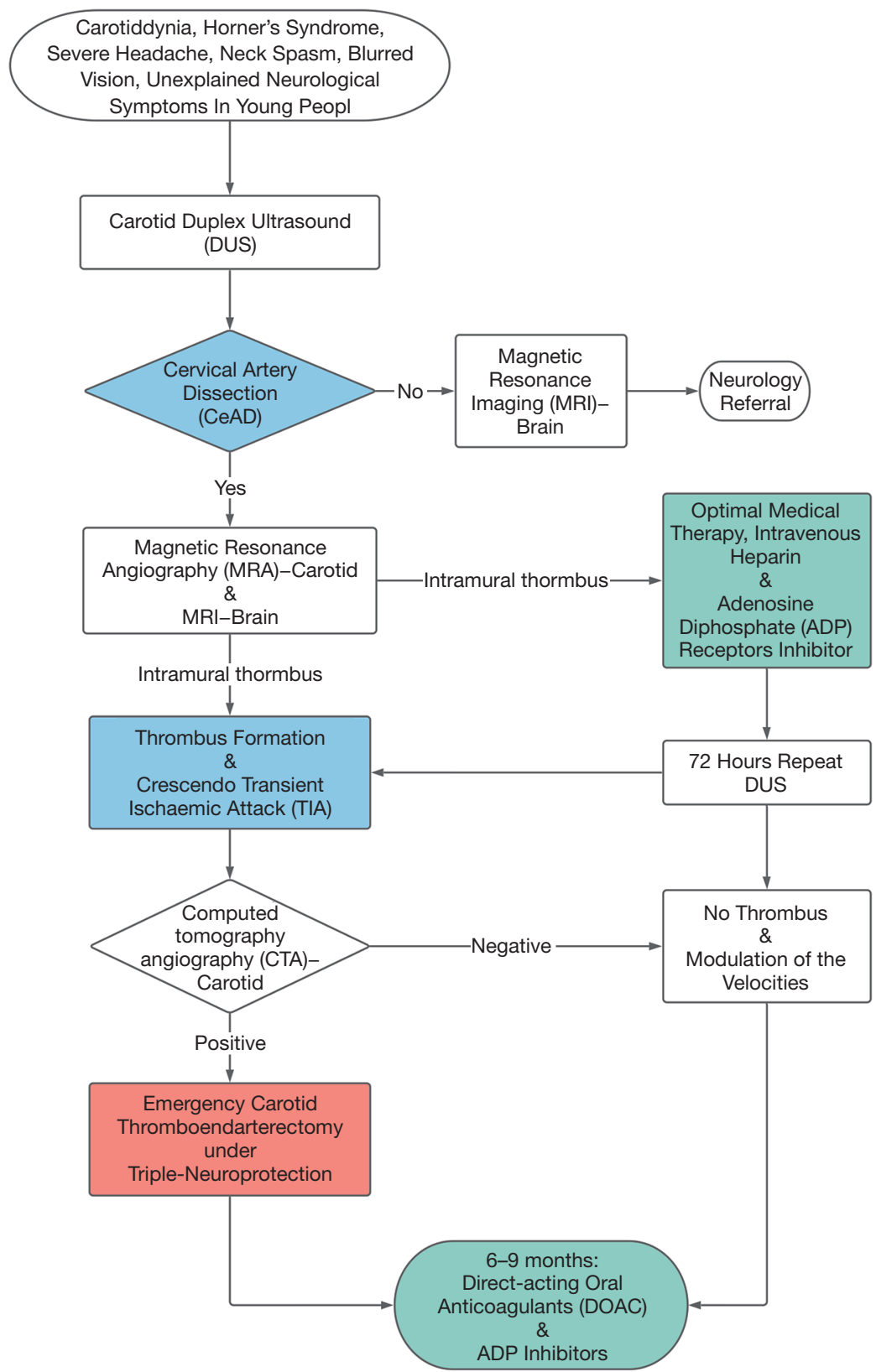

Figure 2 Flow diagram showing the management approach employed in symptomatic patients with acute carotid artery dissection.

Nine patients had carotid thrombo-endarterectomy with synthetic patch, one patient had a biological patch and one had an eversion endarterectomy. Over their entire follow up, only one patient, who had a biological patch, required reintervention with carotid angioplasty and stenting for symptomatic recurrent $99 \%$ stenosis. There was no stroke or death during the follow-up period.

We have summarised our management strategy in
Figure 2. Patients presenting with carotid-dynia, headache, neck spasm, Horner's syndrome, with TIAs, RIND or stroke will undergo emergency duplex ultrasound scan, MRA carotid and brain and start on intra venous heparin aiming at APPT of 70-90. In addition, they will begin oral clopidogrel and sodium nitroprusside to gently lower the blood pressure. Embolisation from thrombus at the carotid dissection site plays a major part in stroke pathogenesis as 
most strokes occur soon after initial onset of symptoms. We advocate the use of a combination of anticoagulation with a direct oral anticoagulant (DOAC) with clopidogrel from presentation up to 6-12 months after dissection.

If patients' neurological deficit is not resolved, and there is persistence of flow limiting pattern on duplex, a CTA carotid is performed, IV heparin is stopped and patients are subjected to carotid thrombo-endarterectomy with patching under triple neuroprotection $(82,83)$. Post-operative the patients are discharged on clopidogrel $75 \mathrm{mg}$, once daily with DOAC for 6 months.

Furthermore, patients with carotid and vertebral dissection can develop pseudoaneurysm, rate of development ranging from $5 \%$ to $40 \%(39,62)$. Notably, post dissection carotid pseudoaneurysm must be dealt surgically in young patients.

\section{Mapping for the future}

Spontaneous Cervical Artery Dissection (sCAD) (41) has tentative associations with major or minor trauma, recent infection, migraine, hypertension, hyperhomocysteinaemia, low levels of $\alpha 1$-antitrypsin, and fibromuscular dysplasia (84). However, population-based studies, supplemented by histopathology, suggest that the underlying cause is unlikely to be mechanical, but it may be spontaneous or idiopathic $(13,85)$. The spontaneity of this condition and the young age of presentation points to an underlying connective tissue defect, which has led researchers to explore the possibility of an associated specific genetic mutation encoding for a particular structural component of the arterial connective tissue (1,86-94).

Evidence from large-scale studies, undertaken by the Cervical Artery Dissection and Ischemic Stroke Patients (CADISP) study group support a genetic predisposition to sCAD (89). However, the underlying causative candidate gene/genes have not been confirmed [111-116]. Candidate genes including, COL3A1, ICAM-1, COL5A2, MTHFR and PHACTR1 have been investigated, with tentatively positive, albeit inconsistent results $(84,88)$. Therefore, disease expression, or phenotype needs to be accurately established in individual patients because phenotype, even in the absence of genotype, will help to determine arterial fragility and management options.

Biomarkers are increasingly used in clinical practice as measurable indicators of presence and severity of a disease. Understanding the underlying injury and the chronological progression of the disease can enhance the usefulness of biomarkers. Matrix-metalloproteinases (MMPs) are involved in the balance between synthesis and degradation of the arterial wall. MMP-2 has been shown to have a significant role to play in cervical artery dissection, in particular in patients with spontaneous and/ or multiple dissections and can correlate with disease severity. Moreover, serum neurofilament light chain (sNFL) levels, has been shown to be routinely present in patients with stroke, and is correlated with clinical severity and had temporal prognostic value relative to the time point of blood sampling (95-99).

Contemporary advances to in vivo arterial imaging are currently used to quantify macro-function and are related to arterial wall structure. In particular, dynamic and phase contrast MRI provide quantitative outputs in arterial function such as peak flow velocities, flow vectors, wall shear stress and arterial compliance. Appreciating functional interaction of arterial soft tissue with dynamic blood flow is particularly relevant in the context of arterial wall dysfunction, which results from connective tissue disease (89,95-100).

Combining biomarkers with MRI offers immense potential for enhanced diagnostic capabilities. Molecular imaging with positron emission tomography, when added to MRI, combines biomarkers with imaging to reveal the underlying pathological process. This combination is particularly useful for patients with sCAD who are being managed medically, but in whom an accurate assessment of when to definitively intervene is lacking. The use of imaging combined with biomarkers of molecular pathway will allow identification of stroke-risk, arterial spasm, pseudo-aneurysm formation or further dissection.

\section{Conclusions}

In the absence of robust evidence, CeAD in patients with evolving neurological symptoms despite medical therapy remains a situation when a bedside clinician should use, on a case-by-case basis, a personalised precision approach. These patients should be treated in a high deliberate practice volume centre, where best clinical judgment, that comes with operator experience is executed through a stepwise care approach.

Although observational data suggest that endovascular therapy can be used in CeAD when antithrombotic therapy fails or hemodynamic infarction is impending, intuitively carotid surgery should be preferentially considered in young healthy patients. In these cases, which are invariably acute with active neurological deficit, carotid surgery should be performed under triple neuroprotection. Endovascular 
therapy remains an option if surgery is contraindicated and/ or the lesion is anatomically un-accessible.

The combined use of cervical arterial macro-function and 4D MRI with molecular biomarkers, offers immense potential for enhanced diagnostic capabilities and will allow identification of stroke-risk, arterial spasm, pseudo-aneurysm formation or further dissection. These further imaging techniques will help in the formulation of algorithms for intervention versus optimal medical treatment.

\section{Implications for research}

The absence of any evidence points to the need for an RCT. However, the logistical difficulties of such an undertaking should not be underestimated. In order to recruit large numbers and obtain sufficient funding, an international collaboration is necessary. This is all the more pertinent when trying to recruit a subgroup of patients with sCAD who are neurological symptomatic despite antithrombotic therapy. Given the anticipated difficulties in recruitment, there are high risks of a type II error or of a premature cessation of the trial. Even with ample patient numbers and fiscal support, several other methodological issues still exist. It is likely that in a RCT, the event rate would be lower than death and disability rate obtained from meta-analysis of historical series, therefore, proxy endpoints such as imaging or biomarker endpoints are necessary.

\section{Acknowledgments}

Funding: None.

\section{Footnote}

Provenance and Peer Review: This article was commissioned by the Guest Editor (Kosmas I. Paraskevas) for the series "Carotid Artery Stenosis and Stroke - Prevention and Treatment Part II" published in Annals of Translational Medicine. The article has undergone external peer review.

Reporting Checklist: The authors have completed the PRISMA reporting checklist. Available at http://dx.doi. org/10.21037/atm-20-7279

Conflicts of Interest: All authors have completed the ICMJE uniform disclosure form (available at http://dx.doi. org/10.21037/atm-20-7279). The series "Carotid Artery
Stenosis and Stroke - Prevention and Treatment Part II" was commissioned by the editorial office without any funding or sponsorship. The authors have no other conflicts of interest to declare.

Ethical Statement: The authors are accountable for all aspects of the work in ensuring that questions related to the accuracy or integrity of any part of the work are appropriately investigated and resolved.

Open Access Statement: This is an Open Access article distributed in accordance with the Creative Commons Attribution-NonCommercial-NoDerivs 4.0 International License (CC BY-NC-ND 4.0), which permits the noncommercial replication and distribution of the article with the strict proviso that no changes or edits are made and the original work is properly cited (including links to both the formal publication through the relevant DOI and the license). See: https://creativecommons.org/licenses/by-nc-nd/4.0/.

\section{References}

1. Debette S, Leys D. Cervical-artery dissections: predisposing factors, diagnosis, and outcome. Lancet Neurol 2009;8:668-78.

2. Schievink WI. Spontaneous dissection of the carotid and vertebral arteries. N Engl J Med 2001;344:898-906.

3. Schwartz NE, Vertinsky AT, Hirsch KG, et al. Clinical and radiographic natural history of cervical artery dissections. J Stroke Cerebrovasc Dis 2009;18:416-23.

4. Béjot Y, Aboa-Eboulé C, Debette S, et al. Characteristics and outcomes of patients with multiple cervical artery dissection. Stroke 2014;45:37-41.

5. Smajlović D. Strokes in young adults: epidemiology and prevention. Vascular health and risk management 2015;11:157-64.

6. Biller J, Sacco RL, Albuquerque FC, et al. Cervical arterial dissections and association with cervical manipulative therapy: a statement for healthcare professionals from the american heart association/american stroke association. Stroke 2014;45:3155-74.

7. Engelter ST, Traenka C, Von Hessling A, et al. Diagnosis and Treatment of Cervical Artery Dissection. Neurol Clin 2015;33:421-41.

8. CADISS Trial Investigators. Antiplatelet treatment compared with anticoagulation treatment for cervical artery dissection (CADISS): a randomised trial. Lancet Neurol 2015;14:361-7. 
9. Arnold M, Fischer U, Bousser MG. Treatment issues in spontaneous cervico-cephalic artery dissections. Int J Stroke 2011;6:213-8.

10. Caplan LR. Dissections of brain-supplying arteries. Nat Clin Pract Neurol 2008;4:34-42.

11. Martinelli O, Venosi S, BenHamida J, et al. Therapeutical Options in the Management of Carotid Dissection. Ann Vasc Surg 2017;41:69-76.

12. Vishteh AG, Marciano FF, David CA, et al. Longterm graft patency rates and clinical outcomes after revascularization for symptomatic traumatic internal carotid artery dissection. Neurosurgery 1998;43:761-7; discussion 767-8.

13. Müller BT, Luther B, Hort W, et al. Surgical treatment of 50 carotid dissections: indications and results. J Vasc Surg 2000;31:980-8.

14. Donas KP, Mayer D, Guber I, et al. Endovascular repair of extracranial carotid artery dissection: current status and level of evidence. J Vasc Interv Radiol 2008;19:1693-8.

15. Fava M, Meneses L, Loyola S, et al. Carotid artery dissection: endovascular treatment. Report of 12 patients. Catheter Cardiovasc Interv 2008;71:694-700.

16. Cohen JE, Gomori JM, Itshayek E, et al. Single-center experience on endovascular reconstruction of traumatic internal carotid artery dissections. J Trauma Acute Care Surg 2012;72:216-21.

17. Jeon P, Kim BM, Kim DI, et al. Emergent self-expanding stent placement for acute intracranial or extracranial internal carotid artery dissection with significant hemodynamic insufficiency. AJNR Am J Neuroradiol 2010;31:1529-32.

18. Lyrer P, Engelter S. Antithrombotic drugs for carotid artery dissection. Cochrane Database Syst Rev 2010;10:CD000255.

19. Higgins JPT, Green S (editors). Cochrane Handbook for Systematic Reviews of Interventions Version 5.1.0 [updated March 2011]. The Cochrane Collaboration, 2011. Available online: www.cochrane-handbook.org

20. Hynes N, Kavanagh EP, Tawfick W, et al. Surgical and radiological interventions for treating symptomatic extracranial cervical artery dissection. Cochrane Database Syst Rev 2018;9:CD013118.

21. Liberati A, Altman DG, Tetzlaff J, et al. The PRISMA statement for reporting systematic reviews and metaanalyses of studies that evaluate health care interventions: explanation and elaboration. PLoS Med 2009;6:e1000100.

22. O'Connor D, Green S, Higgins JPT. Chapter 5: Defining the review question and developing criteria for including studies. Cochrane Handbook of Systematic Reviews of Intervention 2011. Version 5.1.0. [Online] The Cochrane Collaboration Available: www.handbook.cochrane.org [Accessed 29 September 2017].

23. Lichy C, Metso A, Pezzini A, et al. Predictors of delayed stroke in patients with cervical artery dissection. Int J Stroke 2015;10:360-3.

24. Brott TG, Halperin JL, Abbara S, et al. 2011 ASA/ACCF/ AHA/AANN/AANS/ACR/ASNR/CNS/SAIP/SCAI/ SIR/SNIS/SVM/SVS guideline on the management of patients with extracranial carotid and vertebral artery disease: a report of the American College of Cardiology Foundation/American Heart Association Task Force on Practice Guidelines, and the American Stroke Association, American Association of Neuroscience Nurses, American Association of Neurological Surgeons, American College of Radiology, American Society of Neuroradiology, Congress of Neurological Surgeons, Society of Atherosclerosis Imaging and Prevention, Society for Cardiovascular Angiography and Interventions, Society of Interventional Radiology, Society of NeuroInterventional Surgery, Society for Vascular Medicine, and Society for Vascular Surgery. J Am Coll Cardiol 2011;57:e16-94.

25. Cervical Artery Dissection in Stroke Study Trial Investigators. Antiplatelet therapy vs. anticoagulation in cervical artery dissection: rationale and design of the Cervical Artery Dissection in Stroke Study (CADISS). International Journal of Stroke 2007;2:292-6.

26. Hatano S. Experience from a multicentre stroke register: a preliminary report. Bull World Health Organ 1976;54:541-53.

27. Uk-Tia Study Group. United Kingdom transient ischaemic attack (UK-TIA) aspirin trial: interim results. UK-TIA Study Group. Br Med J (Clin Res Ed) 1988;296:316-20.

28. Parmar MK, Torri V, Stewart L. Extracting summary statistics to perform meta-analyses of the published literature for survival endpoints. Stat Med 1998;17:2815-34.

29. Tierney JF, Stewart LA, Ghersi D, et al. Practical methods for incorporating summary time-to-event data into metaanalysis. Trials 2007;8:16.

30. Review Manager (RevMan) [Computer program]. Version 5.3. Copenhagen: The Nordic Cochrane Centre, the Cochrane Collaboration, 2014.

31. Atkins D, Best D, Briss PA, et al. Grading quality of evidence and strength of recommendations. BMJ 2004;328:1490.

32. Arauz A, Hoyos L, Espinoza C, et al. Dissection of cervical 
arteries: Long-term follow-up study of 130 consecutive cases. Cerebrovasc Dis 2006;22:150-4.

33. Biller J, Hingtgen WL, Adams HP, et al. Cervicocephalic arterial dissections. A ten-year experience. Arch Neurol 1986;43:1234-8.

34. Biousse V, D'Anglejan-Chatillon J, Massiou H, et al. Head pain in non-traumatic carotid artery dissection: A series of 65 patients. Cephalalgia 1994;14:33-6.

35. Biousse V, Schaison M, Touboul PJ, et al. Ischemic optic neuropathy associated with internal carotid artery dissection. Arch Neurol 1998;55:715-9.

36. Bogousslavsky J, Despland PA, Regli, F. Spontaneous carotid artery dissection with acute stroke. Arch Neurol 1987;44:137-40.

37. Campos CR, Evaristo EF, Yamamoto FI, et al. Spontaneous cervical carotid and vertebral arteries dissection: study of 48 patients. Arq Neuropsiquiatr 2004;62:492-8.

38. Ehrenfeld WK, Wylie EJ. Spontaneous dissection of the internal carotid artery. Arch Surg 1976;111:1294-301.

39. Guillon B, Brunereau L, Biousse V, et al. Long-term follow-up on aneurysms developed during extracranial internal artery dissection. Neurology 1999;53:117-22.

40. Jensen J, Salottolo K, Frei D, et al. Comprehensive analysis of intra-arterial treatment for acute ischemic stroke due to cervical artery dissection. J Neurointerv Surg 2017;9:654-8.

41. Lee VH, Brown RD Jr, Mandrekar JN, et al. Incidence and outcome of cervical artery dissection: a populationbased study. Neurology 2006;67:1809-12.

42. Mokri B. Traumatic and spontaneous extracranial internal carotid artery dissections. J Neurol 1990;237:356-61.

43. Mokri B, Sundt TM, Houser W, et al. Spontaneous dissection of the cervical internal carotid artery. Ann Neurol 1986;19:126-38.

44. Molina CA, Alvarez-Sabin J, Schonewille W, et al. Cerebral microembolism in acute spontaneous internal carotid artery dissection. Neurology 2000;5 5:1738-40.

45. Schievink WI, Piepgras DG, McCaffrey TV, et al. Surgical treatment of extracranial carotid artery dissecting aneurysms. Neurosurgery 1994;35:809-15.

46. Sturzenegger M. Spontaneous internal carotid artery dissection: early diagnosis and management in 44 patients. J Neurol 1995;242:231-8.

47. Vanneste JAL, Davies G. Spontaneous dissection of cervical internal carotid artery. Clin Neurol Neurosurg 1984;86:307-14.

48. Watridge CB, Muhlbauer MS, Lowery RD. Traumatic carotid artery dissection: diagnosis and treatment. J
Neurosurg 1989;71:854-7.

49. Zelenock GB, Kazmers A, Whitehouse WM, et al. Extracranial internal carotid artery dissections. Arch Surg 1982;117:425-32.

50. Bakke SJ, Smith HJ, Kerty E, et al. Cervicocranial artery dissection. Detection by Doppler ultrasound and MR angiography. Acta Radiologica 1996;37:529-34.

51. Bassetti C, Carruzzo A, Sturzenegger M, et al. Recurrence of cervical artery dissection. A prospective study of 81 patients. Stroke 1996;27:1804-7.

52. Beletsky V, Nadareishvili Z, Lynch J, et al. Cervical arterial dissection: time for a therapeutic trial? Stroke 2003;34:2856-60.

53. Campos CR, Calderaro M, Scaff M, et al. Primary headaches and painful spontaneous cervical artery dissection. J Headache Pain 2007;8:180-4.

54. Caso V, Paciaroni M, Corea F, et al. Recanalization of cervical artery dissection: influencing factors and role in neurological outcome. Cerebrovasc Dis 2004;17:93-7.

55. Cimini N, D'Andrea P, Gentile M, et al. Cervical artery dissection: a 5-year prospective study in the Belluno district. Eur Neurol 2004;52:207-10.

56. Engelter ST, Dallongeville J, Kloss M, et al. Thrombolysis in cervical artery dissection--data from the Cervical Artery Dissection and Ischaemic Stroke Patients (CADISP) database. Eur J Neurol 2012;19:1199-206.

57. Engelter ST, Lyrer PA, Kirsch EC, et al. Long-term followup after extracranial internal carotid artery dissection. Eur Neurol 2000;44:199-204.

58. Engelter ST, Rutgers MP, Hatz F, et al. Intravenous thrombolysis in stroke attributable to cervical artery dissection. Stroke 2009;40:3772-6.

59. Kennedy F, Lanfranconi S, Hicks C, et al. Antiplatelets vs anticoagulation for dissection: CADISS nonrandomized arm and meta-analysis. Neurology 2012;79:686-9.

60. Machet A, Fonseca AC, Oppenheim C, et al. Does anticoagulation promote mural hematoma growth or delayed occlusion in spontaneous cervical artery dissections? Cerebrovasc Dis 2013;35:175-81.

61. Traenka C, Gensicke H, Schaedelin S, et al. Biomarkers and antithrombotic treatment in cervical artery dissection Design of the TREAT-CAD randomised trial. Eur Stroke J 2020;5:309-19.

62. Touze E, Randoux B, Meary E, et al. Aneurysmal forms of cervical artery dissection. Stroke 2001;32:418-23.

63. Weimar C, Kraywinkel K, Hagemeister C, et al. Recurrent stroke after cervical artery dissection. J Neurol Neurosurg Psychiatry 2010;81:869-73. 
64. Bassi P, Lattuada P, Gomitoni A. Cervical cerebral artery dissection: a multicenter prospective study (preliminary report). Neurol Sci 2003;24 Suppl 1:S4-7.

65. Biousse V, D'Anglejan-Chatillon J, Touboul PJ, et al. Time course of symptoms in extracranial carotid artery dissections. A series of 80 patients. Stroke 1995;26:235-9.

66. Larsson SC, King A, Madigan J, et al. Prognosis of carotid dissecting aneurysms. Neurology 2017;88:646-52.

67. Pieri A, Spitz M, Valiente RA, et al. Spontaneous carotid and vertebral arteries dissection in a multiethnic population. Arq Neuropsiquiatr 2007;65:1050-5.

68. Arnold M, Pannier B, Chabriat H, et al. Vascular risk factors and morphometric data in cervical artery dissection: a case-control study. J Neurol Neurosurg Psychiatry 2009;80:232-4.

69. Marnat G, Mourand I, Eker O, et al. Endovascular Management of Tandem Occlusion Stroke Related to Internal Carotid Artery Dissection Using a Distal to Proximal Approach: Insight from the RECOST Study. AJNR Am J Neuroradiol 2016;37:1281-8.

70. Menon R, Kerry S, Norris JW, et al. Treatment of cervical artery dissection: a systematic review and meta-analysis. J Neurol Neurosurg Psychiatry 2008;79:1122-7.

71. Sarikaya H, da Costa BR, Baumgartner RW, et al. Antiplatelets versus anticoagulants for the treatment of cervical artery dissection: Bayesian meta-analysis. PLoS One 2013;8:e72697.

72. Bonati LH, Jongen LM, Haller S, et al. New ischaemic brain lesions on MRI after stenting or endarterectomy for symptomatic carotid stenosis: a substudy of the International Carotid Stenting Study (ICSS). Lancet Neurol 2010;9:353-62.

73. Bonati LH, Lyrer PA, Fluri F. Cerebral microbleeds after carotid revascularization -a prospective MRI study. Cerebrovasc Dis 2008;(Supply 2):55.

74. Droste DW, Junker K, Stogbauer F, et al. Clinically silent circulating microemboli in 20 patients with carotid or vertebral artery dissection. Cerebrovasc Dis 2001;12:181-5.

75. Ahlhelm F, Benz RM, Ulmer S, et al. Endovascular treatment of cervical artery dissection: ten case reports and review of the literature. Interv Neurol 2013;1:143-50.

76. Assadian A, Senekowitsch C, Rotter R, et al. Long-term results of covered stent repair of internal carotid artery dissections. J Vasc Surg 2004;40:484-7.

77. Edgell RC, Abou-Chebl A, Yadav JS. Endovascular management of spontaneous carotid artery dissection. J Vasc Surg 2005;42:854-60; discussion 860.
78. Rahme RJ, Aoun SG, McClendon J Jr, et al. Spontaneous cervical and cerebral arterial dissections: diagnosis and management. Neuroimaging Clin N Am 2013;23:661-71.

79. Pham MH, Rahme RJ, Arnaout O, et al. Endovascular stenting of extracranial carotid and vertebral artery dissections: a systematic review of the literature. Neurosurgery 2011;68:856-66.

80. Goyal MS, Derdeyn CP. The diagnosis and management of supraaortic arterial dissections. Curr Opin Neurol 2009;22:80-9.

81. Rao AS, Makaroun MS, Marone LK, et al. Long-term outcomes of internal carotid artery dissection. J Vasc Surg 2011;54:370-4.

82. Sultan S, Dulai M, Laffey J, et al. Safety of Triple Neuroprotection with Targeted Hypothermia, Controlled Induced Hypertension, and Barbiturate Infusion during Emergency Carotid Endarterectomy for Acute Stroke after Missing the 24 Hours Window Opportunity. Ann Vasc Surg 2020;69:163-73.

83. Sultan S, Acharya Y, Barrett N, et al. A pilot protocol and review of triple neuroprotection with targeted hypothermia, controlled induced hypertension, and barbiturate infusion during emergency carotid endarterectomy for acute stroke after failed tPA or beyond 24-hour window of opportunity. Ann Transl Med 2020;8:1275.

84. Debette S, Markus HS. The Genetics of Cervical Artery Dissection. A Systematic Review. Stroke 2009;40:e459-66.

85. Rothwell DM, Brondy SJ, Wiliams JI. Chiropractic manipulation and stroke. A population-based case control study. Stroke 2001;32:1054-60.

86. Rubinstein SM, Peerdeman SM, van Tulder MW, et al. A systematic review of the risk factors for cervical artery dissection. Stroke 2005;36:1575-80.

87. Debette S, Metso T, Pezzini A, et al. Association of vascular risk factors with cervical artery dissection and ischemic stroke in young adults. Circulation 2011;123:1537-44.

88. Debette S, Kamatani Y, Metso TM, et al. Common variation in PHACTR1 is associated with susceptibility to cervical artery dissection. Nat Genet 2015;47:78-83.

89. Debette S, Metso TM, Pezzini A, et al. CADISP-genetics: an International project searching for genetic risk factors of cervical artery dissections. Int J Stroke 2009;4:224-30.

90. Oderich GS, Panneton JM, Bower TC, et al. The spectrum, management and clinical outcome of EhlersDanlos syndrome type IV: a 30-year experience. J Vasc Surg 2005;42:98-106. 
91. Schievink WI, Mokri B, Piepgras DG, et al. Recurrent spontaneous arterial dissections: risk in familial versus nonfamilial disease. Stroke 1996;27:622-4.

92. Brandt T, Hausser I, Orberk E, et al. Ultrastructural connective tissue abnormalities in patients with spontaneous cervico-cerebral artery dissections. Ann Neurol 1998;44:281-5.

93. Brandt T, Orberk E, Weber R, et al. Pathogenesis of cervical artery dissections: association with connective tissue abnormalities. Neurology 2001;57:24-30.

94. Ulbricht D, Diederich NJ, Hermanns-Le T, et al. Cervical artery dissection: an atypical presentation with EhlersDanlos-like collagen pathology? Neurology 2004;63:1708-10.

95. Traenka C, Disanto G, Seiffge DJ, et al. Serum Neurofilament Light Chain Levels Are Associated with Clinical Characteristics and Outcome in Patients with Cervical Artery Dissection. Cerebrovasc Dis

Cite this article as: Sultan S, Hynes N, Acharya Y, Kavanagh E, Jordan F. Systematic review of the effectiveness of carotid surgery and endovascular carotid stenting versus best medical treatment in managing symptomatic acute carotid artery dissection. Ann Transl Med 2021;9(14):1212. doi: 10.21037/ atm-20-7279
2015;40:222-7.

96. Völker W, Besselmann M, Dittrich R, et al. Generalized arteriopathy in patients with cervical artery dissection. Neurology 2005;64:1508-13.

97. Creane A, Maher E, Sultan S, et al. A remodelling metric for angular fibre distributions and its application to diseased carotid bifurcations. Biomech Model Mechanobiol 2012;11:869-82.

98. Creane A, Maher E, Sultan S, et al. Prediction of fibre architecture and adaptation in diseased carotid bifurcations. Biomech Model Mechanobiol 2011;10:831-43.

99. Kinner S, Eggebrecht H, Maderwald S, et al. Dynamic MR Angiography in Acute Aoprtic dissecton. J Magn Reson Imaging 2015;42:505-14.

100. Guillon B, Peynet J, Bertrand M, et al. Do extracellularmatrix-regulating enzymes play a role in cervical artery dissection? Cerebrovasc Dis 2007;23:299-303. 
Supplementary

Appendix 1: Comprehensive search plan based on population, intervention, compartor and outcomes (PICO) with sample search terms employed in Medline Ovid

\begin{tabular}{|c|c|}
\hline Details & $\begin{array}{l}\text { This search is required for the following systematic review: } \\
\text { Surgical and radiological interventions for treating symptomatic cervical artery dissection. }\end{array}$ \\
\hline Population & $\begin{array}{l}\text { Participants with a clinical diagnosis of symptomatic extracranial carotid artery and/or vertebral artery } \\
\text { dissections will be included if associated with active neurological symptoms. }\end{array}$ \\
\hline Intervention and & Radiological intervention plus medical therapy versus medical therapy alone \\
\hline Comparison & Surgical interventional plus medical therapy versus medical therapy alone \\
\hline Outcomes & Not required for search \\
\hline Search terms & 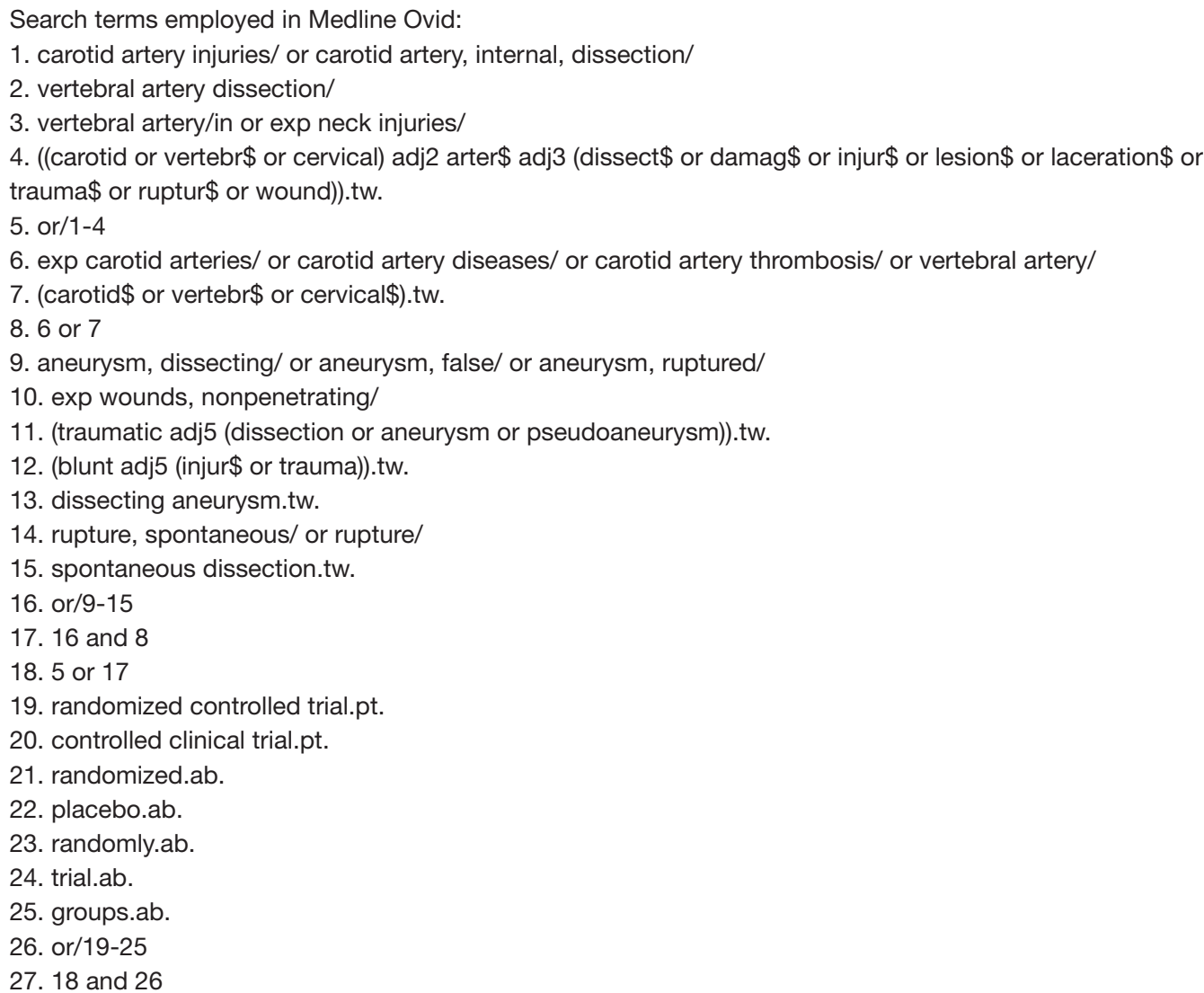 \\
\hline
\end{tabular}

Thesauri to be checked MeSH for CENTRAL and Medline, and Emtree for Embase.

Databases, websites and Cochrane Central Register of Controlled Trials (CENTRAL) (Cochrane Library; latest issue) in the Cochrane registries Library;

MEDLINE Ovid (from 1946)

Embase

Ongoing trials registers:

US National Institutes of Health Ongoing Trials Register ClinicalTrials.gov (www.clinicaltrials.gov/);

World Health Organization (WHO) International Clinical Trials Registry Platform (who.int/ictrp/en/);

Stroke Trials Registry (www.strokecenter.org/trials/).

Database coverage dates To be recorded

Dates of searches

To be recorded

Limits/filters

Stated in protocol: "All search strategies deployed will be combined with subject strategy adaptations of the highly sensitive search strategy designed by the Cochrane Collaboration for identifying randomised controlled trials and controlled clinical trials (as described in the Cochrane Handbook for Systematic Reviews of Interventions Chapter 6, Lefebvre 2011)."

Please note that this is not possible for all search strategies.

Records retrieved from To be recorded

each source

Reference management Endnote X8.2 and Covidence

software 